\title{
PRODUTIVIDADE DO CAPIM-MOMBAÇA SOB DIFERENTES IDADES DE REBROTAÇÃO NO NORTE DO PIAUÍ
}

\author{
ARAUJO, Letícia Maria Barros de ${ }^{1}$ \\ ANDRADE, Alex Carvalho ${ }^{2}$ \\ RODRIGUES, Braz Henrique Nunes ${ }^{3}$ \\ SANTOS, Francisco José de Seixas ${ }^{4}$ \\ MAGALHÃES, João Avelar ${ }^{5}$ \\ RODRIGUES, Rosane Cláudia ${ }^{6}$ \\ OLIVEIRA, Islan Victor Lustosa $\mathrm{de}^{7}$
}

RESUMO: Objetivou-se avaliar a produção do capim-Mombaça sob diferentes idades de rebrotação em Parnaíba-PI. O delineamento experimental utilizado foi em blocos inteiramente casualizados, sendo sete tratamentos constituídos por idades de rebrotação $(7,14,21,28,35,42$ e 49 dias) com três repetições, totalizando 21 unidades experimentais de $6 \mathrm{~m}^{2}$ cada. Todas as parcelas receberam adubação nitrogenada correspondente a $600 \mathrm{~kg} \mathrm{de} \mathrm{N} \mathrm{ha}^{-1}$.ano ${ }^{-1} \mathrm{sob}$ forma de ureia. As variáveis avaliadas foram: teor de matéria seca foliar, teor de matéria seca do colmo, altura, número de perfilhos, porcentagem de folha, porcentagem de colmo, relação folha/colmo, interceptação da radiação fotossinteticamente ativa (IRFA), penetração da radiação fotossinteticamente ativa, índice de área foliar (IAF) e produção de biomassa. Um período de descanso excessivamente longo, comprometeu a estrutura do dossel, ocasionando aumento na produção de biomassa em função do aumento na taxa de alongamento do colmo, redução da relação folha/colmo e diminuição do número de perfilhos. A fim de equilibrar produção e qualidade, recomenda-se para capim-Mombaça em Parnaíba-PI, um período de descanso entre 28 e 33 dias de rebrotação.

Palavras-chave: Panicum maximum. Biomassa. Interceptação luminosa. Índice de área foliar.

\section{PRODUCTIVITY OF THE MOMBAÇA GRASS UNDER DIFFERENT REGROWTH AGES IN NORTH OF PIAUÍ}

\begin{abstract}
SUMMARY: The objective of this study was to evaluate the production of the Mombaça grass under different age of regrowth in Parnaíba-PI. The experimental design was a completely randomized block design, with seven treatments consisting of regrowth ages $(7,14,21,28,35,42$ and 49 days) with three replicates, totaling 21 experimental units of 6 $\mathrm{m}^{2}$ each. All plots received nitrogen fertilization corresponding to $600 \mathrm{~kg} \mathrm{of} \mathrm{N} \mathrm{ha}^{-1}$.ano ${ }^{-1}$ in the form of urea. The variables evaluated were leaf dry matter content, stem dry matter content, height, number of tillers, percentage of leaf, percentage of stem, leaf / stem ratio, interception of photosynthetically active radiation (PAR), radiation penetration photosynthetically leaf area index (LAI) and biomass production. An excessively long rest period compromised the canopy structure, resulting in an increase in biomass production due to an increase in the elongation rate of the stem, a reduction in the leaf / stem ratio and a decrease in the number of tillers. In order to balance production and quality, it is recommended for Mombasa grass in Parnaíba-PI, a resting period between 28 and 33 days of regrowth.
\end{abstract}

Keywords: Panicum maximum. Biomass. Light interception. Leaf area index.

\footnotetext{
${ }^{1}$ Engenheiro Agrônomo, B. Sc., Uespi, Parnaíba, Piauí, Brasil

${ }^{2}$ Zootecnista, D. Sc., Professor da Uespi. Parnaíba, PI.

${ }^{3}$ Engenheiro Agrícola, D. Sc., Pesquisador da EMBRAPA/CPAMN, Parnaíba, PI.

${ }^{4}$ Engenheiro Agrônomo, D. Sc., Pesquisador da EMBRAPA/CPAMN, Parnaíba, PI.

${ }^{5}$ Médico Veterinário, D. Sc., Pesquisador da EMBRAPA/CPAMN, Parnaíba, PI.

${ }^{6}$ Zootecnista, D. Sc., Ufma, Chapadinha, MA

${ }^{7}$ Estudante de Agronomia, Uespi, Parnaíba, PI
} 


\section{INTRODUÇÃO}

Durante os últimos 35 anos houve mudanças significativas no cultivo de pastagem no Brasil. A área de produção total aumentou de cerca de 150 para aproximadamente 180 milhões de hectares, e junto com esse aumento em área as pastagens nativas foram dando lugar às pastagens cultivadas que aumentaram em mais de 300\% nesse período (JANK et al., 2005). Além disso, tem havido crescente interesse em sistemas de produção de leite com base no uso de forrageiras tropicais devido ao seu alto potencial de produção de matéria seca (MS). Taxas de acúmulo de forragem superiores a $100 \mathrm{~kg}$ de MS $\mathrm{ha}^{-1} \cdot \mathrm{dia}^{-1}$ têm sido relatadas para espécies de forrageiras tropicais como Megathyrsus maximus (MOURA et al., 2014).

O capim-Mombaça tem grande repercussão dentro da pecuária brasileira, tendo em vista a elevada produção forrageira, boa aceitabilidade e bom valor nutritivo. Para isso, é necessário um manejo eficiente, que seja capaz de dar à forrageira todas as condições necessárias para expressar o seu potencial. Entretanto, se o período de descanso for muito curto, não haverá tempo suficiente para que a forrageira atinja o índice de área foliar crítico e recupere as suas reservas, colaborando para a diminuição da capacidade de suporte com o decorrer dos ciclos de pastejo e ameaçando a sua perenidade, por outro lado, se o período de descanso for mais longo que o necessário, resulta na senescência e morte das folhas, além do acúmulo de colmo, tornando o sistema de produção ineficiente.

A definição do período de descanso não pode ser generalizada, já que a taxa de crescimento das plantas é diferenciada em função das condições ambientais como estações do ano, do clima, dos solos e da região. No caso de gramíneas tropicais como o capim-Mombaça, fatores como temperatura e luminosidade têm grande peso, sendo os principais responsáveis por causar estacionalidade na produção em determinadas épocas do ano. A disponibilidade hídrica também é um fator essencial, entretanto, é uma barreira que pode ser mais facilmente contornada, quando comparada à necessidade de luz e calor.

O período de descanso, definido através da idade cronológica do dossel, é um método que facilita o manejo do capim. A taxa de crescimento do dossel varia conforme as condições ambientais, portanto, para que esse método seja consistente, ele deve avaliar vários parâmetros que reflitam as condições morfofisiológicas da forrageira, como por exemplo a interceptação da radiação fotossinteticamente ativa (IRFA), o índice de área foliar (IAF), relação folha/colmo e número de perfilhos.

A interceptação de luz aos 95\% resulta na máxima taxa de crescimento (BROUGHAM, 1956), acima desse valor é observado o comprometimento da estrutura do dossel. No caso de gramíneas tropicais, é comum observar o intenso alongamento do colmo, um comportamento que deve ser evitado, já que ocasiona a redução da relação folha/colmo, refletindo negativamente no desempenho animal em função da diminuição da taxa de consumo, redução da digestibilidade e do teor de proteínas.

Objetivou-se com este trabalho avaliar a produtividade do capim-Mombaça sob diferentes idades de rebrotação.

\section{MATERIAL E MÉTODO}

O experimento foi conduzido na fazenda Dez, localizada em Parnaíba-PI, situado na região de abrangência do semiárido (SUDENE, 2017)., durante os meses de setembro e outubro, por 7 sete semanas. O clima da região, de acordo com a classificação climática de Thornthwaite e Mather é C1dA'a', caracterizado como subúmido seco, megatérmico, com pequeno excedente hídrico e uma concentração de $29,7 \%$ da evapotranspiração potencial no trimestre outubro, novembro e dezembro. A normal 
climatológica de precipitação total anual no período de 1978 a 2014 é de 1033,5 mm e no ano de 2015 o total de precipitação foi de 698,4 mm (Bastos et al., 2016).

O solo da área experimental foi classificado como Latossolo Amarelo Distrófico, textura média, fase caatinga litorânea de relevo plano e suavemente ondulado, com as seguintes características químicas nas camadas de 0 a $20 \mathrm{~cm}: \mathrm{MO}=5,54 \mathrm{~g} \mathrm{~kg}^{-1} ; \mathrm{pH} \mathrm{H} \mathrm{H}_{2} \mathrm{O}=6,83 ; \mathrm{P}=5,00 \mathrm{mg} \mathrm{dm}^{-3} ; \mathrm{K}=0,23 \mathrm{cmol}_{\mathrm{c}} \mathrm{dm}^{-3}$; $\mathrm{Ca}=1,37 \mathrm{cmol}_{\mathrm{C}} \mathrm{dm}^{-3} ; \mathrm{Mg}=0,53 \mathrm{cmol}_{\mathrm{c}} \mathrm{dm}^{-3} ; \mathrm{Na}=0,01 \mathrm{cmol}_{\mathrm{c}} \mathrm{dm}^{-3} ; \mathrm{Al}=0,03 \mathrm{cmol}_{\mathrm{c}} \mathrm{dm}^{-3} ; \mathrm{H}+\mathrm{Al}=$ $0,87 \mathrm{cmol}_{\mathrm{c}} \mathrm{dm}^{-3} ; \mathrm{S}=2,14 \mathrm{cmol}_{\mathrm{c}} \mathrm{dm}^{-3} ; \mathrm{CTC}=3,01 ; \mathrm{V}=70,99 \% ; \mathrm{M}=1,38 \%$.

O delineamento experimental utilizado foi em blocos casualizados, constituídos por sete tratamentos, sendo eles as idades de rebrotação $(7,14,21,28,35,42$ e 49 dias) com três repetições, totalizando 21 unidades experimentais de $6 \mathrm{~m}^{2}$ cada. Todas as parcelas receberam adubação nitrogenada correspondente a $600 \mathrm{~kg}$ de $\mathrm{N} \mathrm{ha}^{-1} \mathrm{ano}^{-1}$ sob a forma de ureia, em função das idades de rebrotação.

A área experimental foi irrigada pelo método de aspersão convencional fixo, com lâmina de irrigação de $6 \mathrm{~mm}$ dia $^{-1}$, utilizando espaçamento $10 \mathrm{~m}$ x $12 \mathrm{~m}$. Inicialmente foi realizado um corte de uniformização do capim-Mombaça a vinte e cinco centímetros acima do nível do solo, de forma manual, utilizando facão. Na ocasião, efetuou-se a adubação com nitrogênio em cobertura.

Nas unidades experimentais, antes de cada corte nas referidas idades, foram feitas medições de altura em 4 pontos distintos, com auxílio de uma régua graduada milimétrica colocada ao nível do solo até o ponto de curvatura das folhas superiores. O interceptômetro linear (AccuPAR) foi utilizado para medir a interceptação de luz nos dosséis de cada tratamento acima das plantas e no nível do solo, o que permitiu calcular a interceptação, penetração da radiação fotossinteticamente ativa, e o índice de área foliar.

Nas datas estabelecidas, para cada idade de rebrotação, o material usado para estimativa da produção foi colhido em uma área útil de $1 \mathrm{~m} \times 1 \mathrm{~m}$ à 25 centímetros de altura do solo. Porém, anteriormente, foram coletadas subamostras de $0,25 \mathrm{~m} \mathrm{x} \mathrm{0,25} \mathrm{m}\left(0,0625 \mathrm{~m}^{2}\right)$, para contagem do número de perfilhos. Toda a massa verde colhida na área útil de cada parcela foi levada imediatamente para o laboratório dentro de sacos plásticos, juntamente com as subamostras ensacadas, identificadas individualmente e pesadas.

Após a contagem de perfilhos utilizou-se a subamostra para separação das frações folha e colmo, que foram pesadas, acondicionadas em bandejas, levadas ao forno micro-ondas, e pesadas até atingir um peso constante, possibilitando a determinação do teor de matéria seca de uma forma alternativa e que demanda menos tempo.

Os dados obtidos foram submetidos à análise estatística por meio do programa SISVAR (FERREIRA, 2014). Quando constatada significância pela análise de variância as idades de rebrotação foram submetidas à análise de regressão. A escolha do modelo foi feita com base no coeficiente de determinação, na significância da regressão e dos seus coeficientes, testados pelo teste "t" Student em nível de $5 \%$ de probabilidade e pela lógica biológica da variável em estudo.

\section{RESULTADO E DISCUSSÃO}

O teor de matéria seca foliar (MSF) do capim-Mombaça aumentou linearmente em função das idades de rebrotação, variando de 22,62 a 32,99\% (Figura 1). Os resultados desse trabalho são semelhantes aos de Silva et al. (2007) que ao avaliar as características estruturais e de produção do capimTânzania submetidos a períodos de descanso, verificou elevação da MSF ao longo das idades de rebrotação, sendo cada vez mais acentuada conforme avançava os ciclos de pastejo. Entretanto, Macedo et al. (2010), ao avaliar o efeito de dois períodos de descanso sobre as características morfogênicas, estruturais e o acúmulo de forragem do capim-Mombaça, observaram que dentre as características 
agronômicas avaliadas, apenas a produção de massa seca foliar não foi incrementada com o prolongamento do período de descanso.

FIGURA 1-Estimativa do teor de matéria seca da folha do capim-Mombaça em função de diferentes idades de rebrotação. Parnaíba, Piauí.

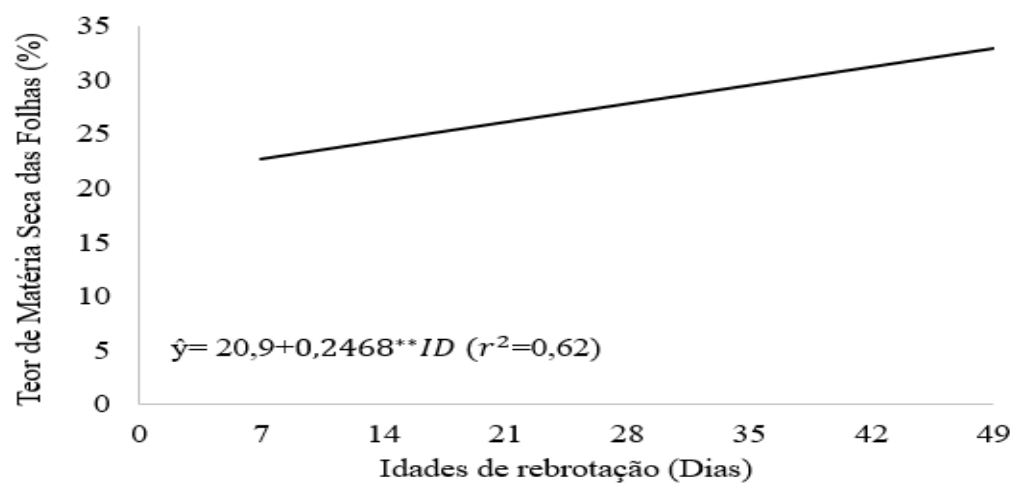

O teor de matéria seca do colmo do capim-Mombaça aumentou linearmente em função da idade de rebrotação, variando de 15,7 a 26,17\% (Figura 2). Segundo Macedo et al. (2010) isso acontece porque um período de descanso prolongado torna a planta menos eficiente, pois a hierarquia de distribuição de assimilados passa a priorizar a produção de colmo. Santos et al. (2011) e Cano et al. (2004) tiveram a mesma conclusão ao observar que no decorrer do período de rebrotação, os processos de alongamento e acúmulo de colmo foram favorecidos.

FIGURA 2-Estimativa do teor de matéria seca do colmo do capim-Mombaça em função de diferentes idades de rebrotação. Parnaíba, Piauí.

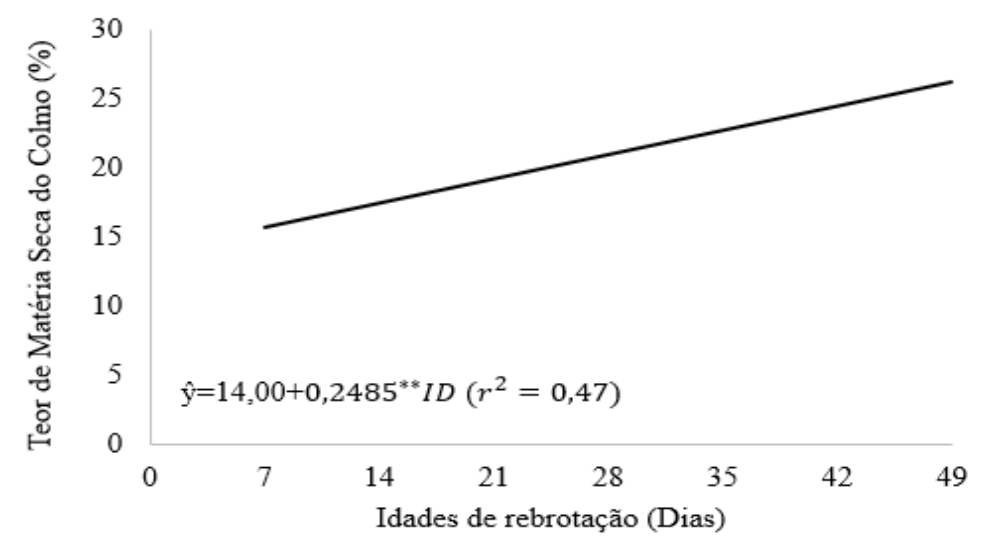

Entre as estratégias de manejo da pastagem, deve-se dar bastante atenção ao controle do alongamento do colmo (ALEXANDRINO et al., 2005), algo muito comum dentre as gramíneas tropicais, mas que deve ser evitado, pois ocasiona redução do desempenho animal em função da sua composição bromatológica.

A altura das plantas do capim-Mombaça aumentou 2,03 cm a cada dia de rebrotação (Figura 3). Os resultados obtidos estão de acordo com Cândido (2003), que afirma que a altura do pasto é consequência do tempo de rebrotação da gramínea e de suas adaptações morfológicas durante esse processo. Santos et al. (2011) ao avaliar o desempenho dos capins Tanzânia e Mombaça consorciados com os estilosantes, observaram que com o avanço do tempo, as gramíneas atingiram maiores alturas. 
FIGURA 3-Estimativa da altura das plantas do capim-Mombaça em função de diferentes idades de rebrotação. Parnaíba, Piauí.

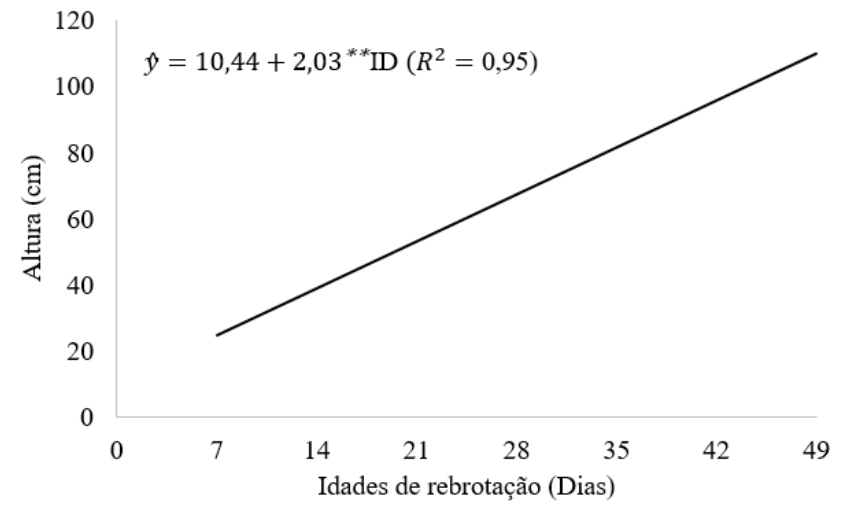

Maiores alturas incrementam os ganhos de produção. Entretanto, é importante verificar até que ponto esse incremento pode ser vantajoso. Cano et al. (2004) ao avaliar a produção de forragem do capimTânzania, observaram no momento do corte que o dossel de menor altura apresentava grande proporção de folhas e colmos finos, enquanto o dossel de maior altura exibia uma grande proporção de colmos grossos e pesados. Dessa forma, entende-se que a altura do dossel pode reduzir a relação folha/colmo e comprometer a qualidade da forragem.

O número de perfilhos variou de maneira quadrática negativa em função das idades de rebrotação, com valor máximo aos 33 dias (Figura 4). A capacidade de perfilhamento é uma característica altamente desejável em plantas forrageiras, pois influencia a produção, a qualidade e a persistência das espécies perenes (ANDRADE et al., 2003). Sbrissia \& Silva (2008), Carnevalli et al. (2006) e Barbosa et al. (2007) verificaram redução da densidade populacional de perfilhos com o aumento do período de descanso e altura de pastejo para capins Marandú, Mombaça e Tanzânia, respectivamente. Conforme Macedo et al. (2010) e Difante et al. (2011), pastos submetidos a longos períodos de descanso teriam um reduzido número de perfilhos, porém se apresentavam maiores e mais pesados.

FIGURA 4-Estimativa do número de perfilhos do capim-Mombaça em função de diferentes idades de rebrotação. Parnaíba, Piauí.

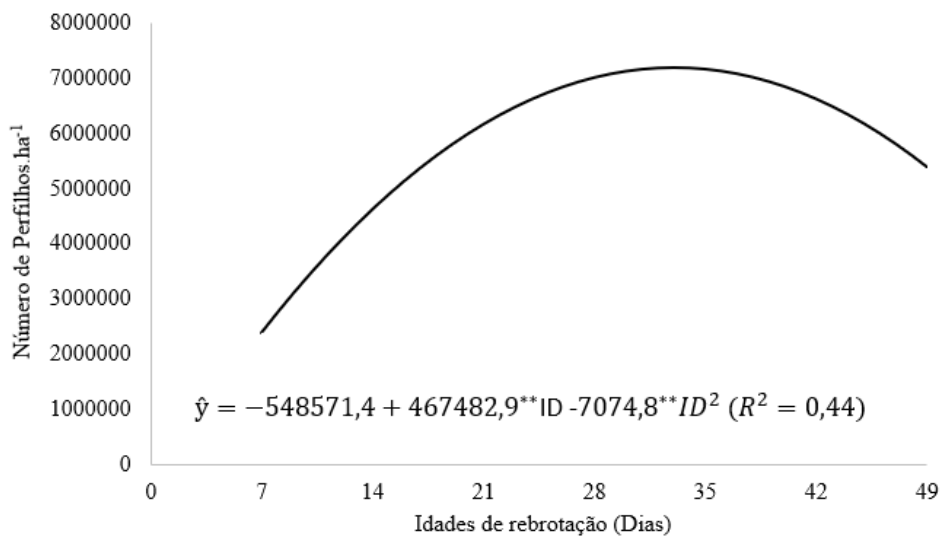

Quando o período de descanso é muito longo, o capim não sente a necessidade de perfilhar continuamente, ao contrário de quando ele é submetido a uma alta frequência a de pastejo, pois nesse caso, o capim procura produzir um maior número de perfilhos na tentativa de sobreviver, esse 
comportamento é conhecido como plasticidade fenotípica. Além disso, Cutrim Junior et al. (2011) afirma que a redução do número de perfilhos com o prolongamento do período de descanso, é causado pelo sombreamento mútuo, já que a luz estimula as gemas basais e axilares para produção de novos perfilhos.

Aos dados de porcentagem de folhas em função das diferentes idades ajustou-se uma equação quadrática negativa, com a máxima proporção de 85,53\% aos 28 dias de rebrotação (Figura 6). Cano et al. (2004) ao avaliar a produção de forragem do capim-Tanzânia em diferentes alturas, obteve resultados diferentes, onde constatou que a porcentagem de folhas sempre ficou acima de $30 \%$ da massa de forragem, independentemente da altura do dossel, que está diretamente ligada a idade de rebrotação. Segundo Stabile et al. (2010), colmo e folhas apresentam composições bromatológicas distintas, e a maturidade afeta de maneira diferente as duas frações, sendo a digestibilidade das folhas pouco afetada, se comparadas ao colmo. Portanto, a redução da porcentagem de folhas causada pelo prolongamento do período de descanso aponta uma perda de qualidade significativa da forragem.

FIGURA 5-Estimativa da porcentagem de folha do capim-Mombaça em função de diferentes idades de rebrotação. Parnaíba, Piauí.

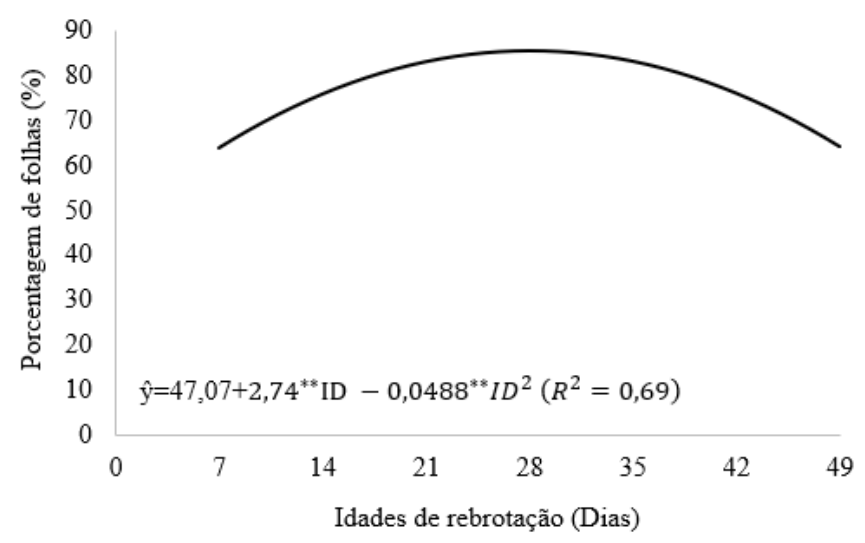

Para a porcentagem de colmo do capim-Mombaça em função das idades de rebrotação ajustou-se uma equação quadrática positiva, onde a menor porcentagem de colmo foi de 14,45\% aos 28 dias. Com o aumento da idade de rebrotação, observa-se maior participação de colmo (GOMIDE et al., 2007; JANUSCKIEWICZ et al., 2010). Cândido et al. (2005) e Cutrim Junior et al. (2011) relataram influência direta do alongamento dos colmos sobre a altura do dossel. Alexandrino et al. (2005), trabalhando com capim-Mombaça, afirma que o alongamento de colmo ocorre quando o IAF está acima do nível crítico, portanto, sendo uma estratégia da planta para que chegue luz de qualidade e em elevada quantidade até as folhas baixeiras. 
FIGURA 6-Estimativa da porcentagem de colmo do capim-Mombaça em função de diferentes idades de rebrotação. Parnaíba, Piauí.

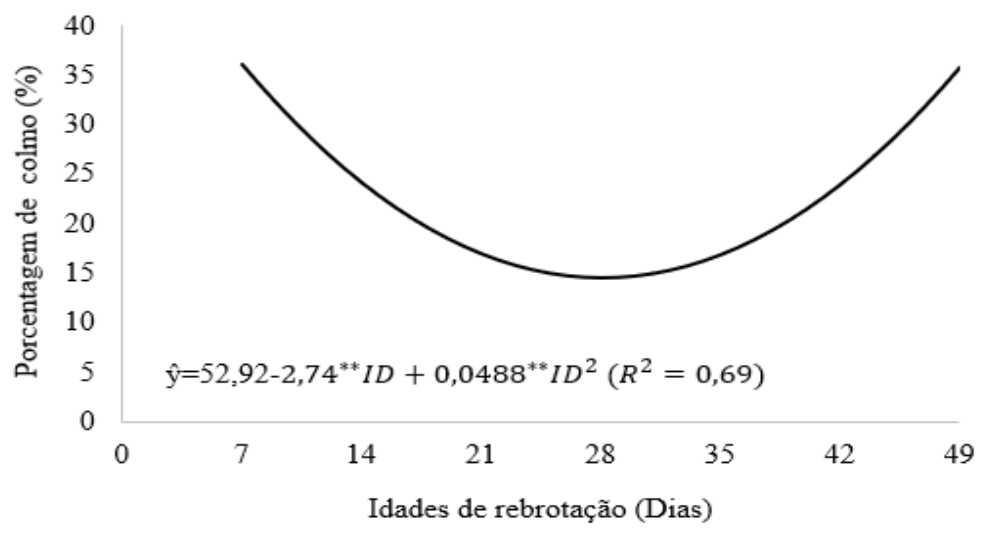

Portanto, a partir de uma determinada idade de rebrotação, após o dossel atingir o IAF crítico, ocorre o aumento da porcentagem de colmo, gerando incrementos à biomassa forrageira, porém, causando diminuição da relação folha/colmo, tornando a produção de forragem pouco eficiente e de baixa qualidade.

Aos dados de relação folha/colmo do capim-Mombaça ajustou-se uma equação quadrática negativa, atingindo o valor máximo de 5,75 aos 26 dias de idade de rebrotação (Figura 7). Brâncio et al. (2003) avaliando a relação folha/colmo do capim-Mombaça, encontrou valores próximos a 4 no final do período seco e início do período chuvoso. Neste trabalho a maior relação folha/colmo foi de 5,75 aos 26 dias de rebrotação, a partir daí, os valores foram diminuindo até 0,89 aos 49 dias de rebrotação, estando abaixo do limite crítico $(1,0)$ para esta relação conforme Pinto et al. (1994), implicando na queda da qualidade da forragem, prejudicando a eficiência do pastejo animal.

FIGURA 7-Estimativa da relação folha/colmo do capim-Mombaça em função de diferentes idades de rebrotação. Parnaíba, Piauí.

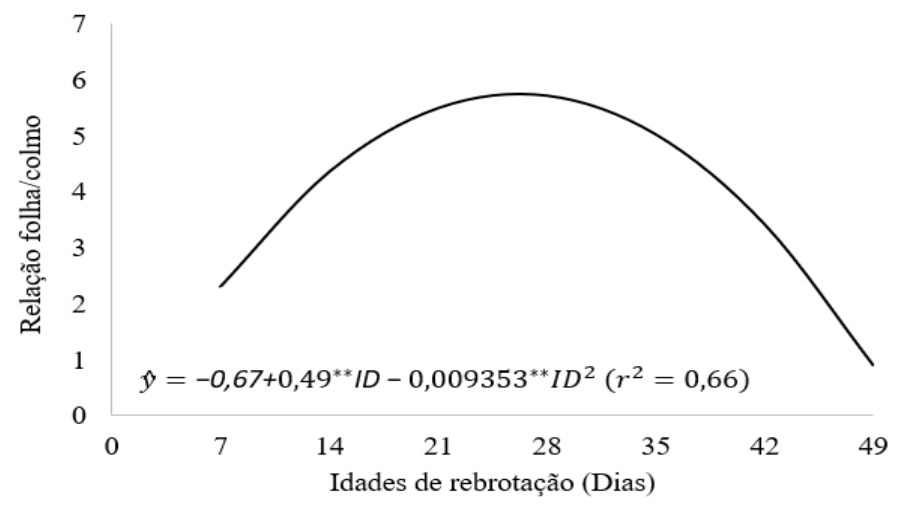

Cândido et al. (2005) verificaram que o prolongamento do período de descanso acarretou maior altura e maior massa seca de forragem verde, porém com proporção crescente de colmos, acarretando acentuada redução na relação folha/colmo para o cultivar Mombaça sob pastejo de lotação intermitente. Gomide et al. (2007) ao avaliar o capim-Mombaça, observou o comprometimento da relação folha/colmo que variou, em média, de 4,6 para 1,7 devido ao aumento da taxa de alongamento do colmo colmo proporcional à duração do período de descanso.

A curva de intercepção da radiação fotossinteticamente ativa (IRFA) apresentou padrão 
assintótico, com valor de 95\% ocorrendo aos 32 dias de idade de rebrotação, quando o IAF era de 3,3. Aos 49 dias de rebrotação, o dossel atingiu 99,42\% de IRFA (Figura 8). Se a idade de rebrotação for longa o suficiente para que o dossel intercepte quase toda a luz incidente, principalmente em gramíneas forrageiras tropicais, pode ocorrer o alongamento de colmos, que altera os padrões de acúmulo de biomassa (PEDREIRA et al., 2007; PEDREIRA et al., 2009). Cândido et al. (2005) verificaram que a idade de rebrotação mais longa influenciou o nível de IRFA, comprometendo a estrutura do dossel. A partir do momento em o que o dossel atinge 95\% de interceptação de luz intensifica ainda mais a produção de colmo, gerando incrementos a biomassa forrageira (ALEXANDRINO et al., 2005; CUTRIM JUNIOR et al., 2011).

FIGURA 8-Estimativa da interceptação da radiação fotossinteticamente ativa (IRFA) do capim-Mombaça em função de diferentes idades de rebrotação. Parnaíba, Piauí.

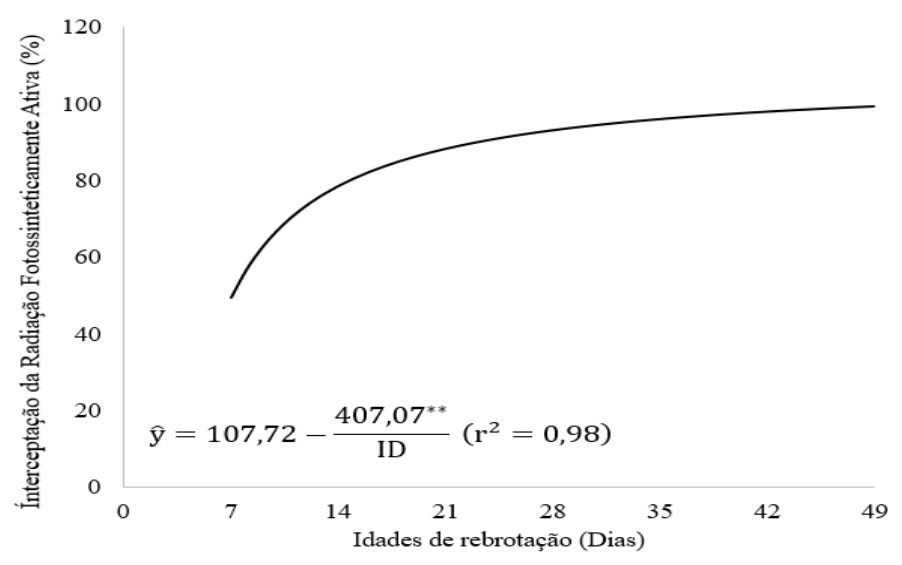

A curva de penetração de luz apresentou padrão assintótico, diminuindo em função das idades de rebrotação (Figura 9). Conforme avançam as idades de rebrotação a penetração de luz no dossel diminui, devido ao aumento da IRFA. A partir do momento em que 95\% da luz é interceptada, a forrageira passa a priorizar a produção de colmos, a fim de fazer com que a luz chegue até a porção inferior do dossel, principalmente nas gemas basais e axilares, que necessitam de estímulo luminoso para a produção de novos perfilhos.

FIGURA 9-Estimativa de penetração luminosa do capim-Mombaça em função de diferentes idades de rebrotação. Parnaíba, Piauí.

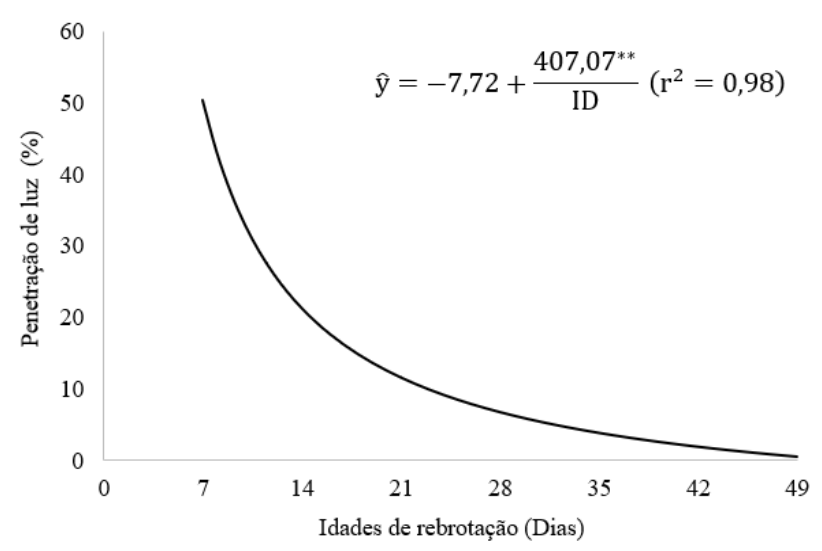

O ambiente pouco luminoso do estrato inferior do dossel compromete sua fotossíntese e a vida útil das folhas próximas ao solo (CÂNDIDO et al., 2005), além disso Cutrim Junior et al. (2011) afirmam que 
um maior coeficiente de extinção luminosa promovido pelo aumento da IRFA, pode contribuir para uma redução na densidade populacional de perfilhos. Sugyiama et al. (1985) afirmam que a produção de colmos é intensificada após $95 \%$ de IRFA, devido a redução da penetração de luz no dossel. Segundo Gomide et al. (2007), o intenso alongamento do colmo sob maiores idades de rebrotação, permitiu maior penetração da luz, tornando a interceptação luminosa mais eficiente. Embora a intensificação de acúmulo de colmo seja uma estratégia de sobrevivência da forrageira em função da baixa penetração de luz no dossel, é algo que deve ser evitado sob o ponto de vista produtivo e econômico, pois tem como consequência redução na relação folha/colmo, perda da qualidade da forragem e diminuição do consumo animal

Aos dados de IAF em função das idades de rebrotação, ajustou-se uma equação assintótica, onde o IAF crítico foi de 3,3 aos 32 dias de idade (Figura 10). Segundo Humphreys (1991), a faixa ótima do índice de área foliar (IAF) para capim-Mombaça, situa-se entre 3 e 5, onde a taxa de crescimento do pasto se estabiliza ou reduz, devido ao sombreamento da porção inferior da planta. Maiores idades de rebrotação propiciam incrementos de IAF, em função de taxas crescentes de fotossíntese do dossel (MELLO \& PEDREIRA, 2004; CÂNDIDO et al., 2005; GOMIDE et al.; 2007).

FIGURA 10-Estimativa do índice de área foliar do capim-Mombaça em função de diferentes idades de rebrotação. Parnaíba, Piauí.

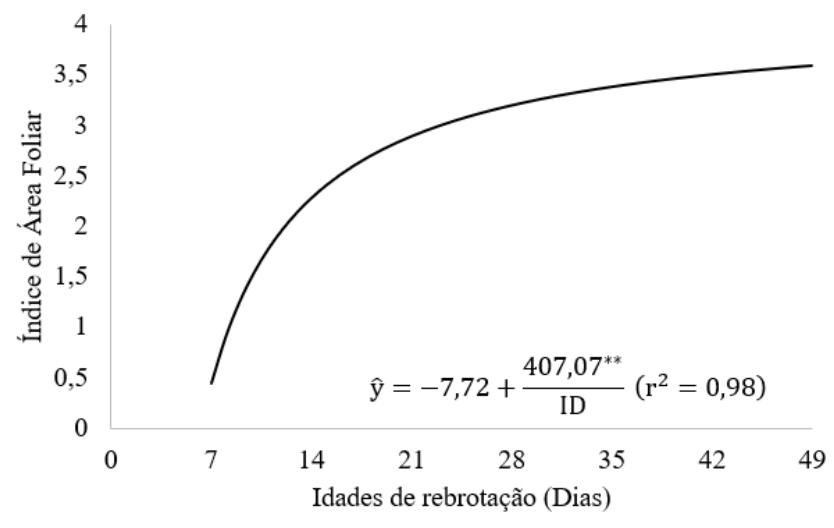

Em condições ambientais favoráveis, a taxa de crescimento cultural é impulsionada pelo aumento do índice de área foliar, que consequentemente aumenta a interceptação luminosa (ALEXANDRINO et al., 2005), Portanto, determinar uma idade de rebrotação adequada é importante para que o dossel tenha condições de produzir folhas o suficiente para atingir o IAF crítico ao nível de $95 \%$ de IRFA, consequentemente, favorecendo a produção de forragem (CANO et al., 2004; CUTRIM JUNIOR et al., 2011).

É fato amplamente reconhecido que quando o pasto intercepta $95 \%$ da luz incidente obtém-se um valor de IAF crítico (BORGES et al., 2011), neste valor crítico a taxa de crescimento de qualquer forrageira estaria próxima do seu valor máximo (BROUGHAM, 1956; DA SILVA; PEDREIRA, 1997).

Para produção de biomassa observou-se um aumento linear positivo em resposta às idades de rebrotação, variando de 0,57 a 6,44 t/ha nas idades de 7 a 49 dias (Figura 11). Os valores das variáveis altura e IAF que aumentaram em função das idades de rebrotação, tiveram grande contribuição para os valores de produção, portanto, justificando o comportamento crescente expresso pela biomassa forrageira durante o período de rebrotação. Gomide et al. (2007) também observaram que o prolongamento do período de descanso causou o aumento da altura do dossel, assim como o de biomassa forrageira. Porém, além da produção de forragem, deve-se levar em consideração a proporção dos componentes da planta 
consumidos pelos animais (folhas e colmos), pois essas frações afetam potencialmente o ganho de peso ou a produção de leite dos animais em pastejo (MORDADO et al. 2009).

FIGURA 11-Estimativa de produção do capim-Mombaça em função de diferentes idades de rebrotação. Parnaíba, Piauí.

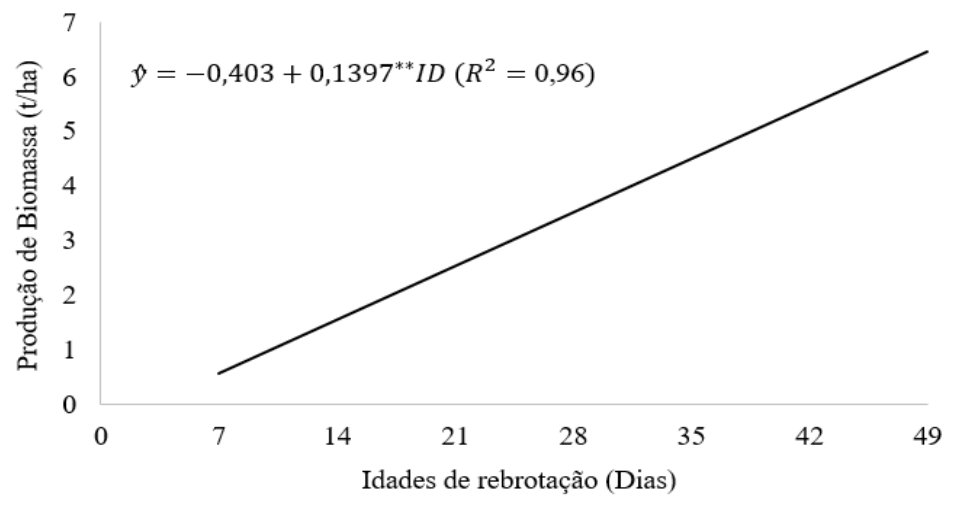

Stobbs (1973) apontou que embora o aumento da idade de rebrotação esteja associada a maiores densidades de biomassa total, geralmente apresenta uma menor densidade de folhas. Isso acontece porque a partir de uma determinada idade de rebrotação, ocorre a diminuição da relação folha/colmo, em decorrência do aumento da taxa de alongamento do colmo. Cândido et al. (2005) observaram que o piquete que estava sob o mais longo período de descanso, teve grande proporção da massa seca formada por colmo, a fração rejeitada pelos animais.

\section{CONCLUSÃO}

A estrutura do dossel do capim-Mombaça foi influenciada pelas idades de rebrotação. A fim de equilibrar produção e qualidade, recomenda-se para capim-Mombaça um período de descanso entre 28 e 33 dias de rebrotação.

\section{REFERÊNCIAS}

ALEXANDRINO, E.; GOMIDE, J.A.; GOMIDE C.A.M. Crescimento e desenvolvimento do dossel de Panicum maximum cv. Mombaça. Revista Brasileira de Zootecnia, v.36, p. 2164- 2173, 2005. http://dx.doi.org/10.1590/S1516-35982005000700002

ANDRADE, A.C. et al. Adubação nitrogenada e potássica em capim-Elefante (Pennisetum purpureum Schun. cv. Napier). Ciencia e Agrotecnologia, Edição especial, p.1643-165, 2003. https://sumarios.org/artigo/aduba\%C3\%A7\%C3\%A3o-nitrogenada-e-pot\%C3\%A1ssica-em-capimelefante-pennisetum-purpureum-schum-cv-napier

BARBOSA, R.A. et al. Capim-Tanzânia submetido a combinações entre intensidade e frequência de pastejo. Pesquisa Agropecuária Brasileira, v.42, p.329-340, 2007. http://dx.doi.org/10.1590/S0100$\underline{204 X 2007000300005}$

BASTOS, E.A.; ANDRADE JUNIOR, A.S. de; RODRIGUES, B.H.N. Boletim agrometeorológico de 2015 para o Município de Parnaíba, Piauí. Teresina: Embrapa Meio-Norte, 2016. 38 p. (Embrapa MeioNorte. Documentos, 240) http://ainfo.cnptia.embrapa.br/digital/bitstream/item/155070/1/Doc-240-Boletim-Parnaiba-2015.pdf 
BORGES, B.M.M.N. et al. Relação entre o fluxo luminoso interceptado em diferentes épocas no índice de área foliar de diferentes forrageiras. Semina: Ciências Agrárias, v. 32, n. 4, p. 1589-1594, 2011.

http://dx.doi.org/10.5433/1679-0359.2011v32n4p1589

BRÂNCIO, P.A. et al. Avaliação de três cultivares de Panicum maximum Jacq. sob pastejo: disponibilidade de forragem, altura do resíduo pós pastejo, e participação de folhas, colmos e material morto. Revista Brasileira de Zootecnia, v.32, n.1, p.55-63, 2003. http://dx.doi.org/10.1590/S1516$\underline{35982003000100007}$

BROUGHAM, R.W. Effect of intensity of defoliation on regrowth of pasture. Australian Journal of Agriculture Research, v.7, n.5, p.377-387, 1956. http://dx.doi.org/10.1071/AR9560377

CÂNDIDO, M.J.D. Morfofisiologia e crescimento do dossel e desempenho animal em Panicum maximum cv. Mombaça sob lotação intermitente com três períodos de descanso. Viçosa, MG: Universidade Federal de Viçosa, 2003. 134f. Tese (Doutorado em Zootecnia) - Universidade Federal de Viçosa, 2003. http://www.locus.ufv.br/handle/123456789/11171

CÂNDIDO, M.J.D. et al. Morfofisiologia do dossel de Panicum maximum cv. Mombaça sob lotação intermitente com três períodos de descanso. Revista Brasileira de Zootecnia, v.34, n.2, p.406-415, 2005. http://dx.doi.org/10.1590/S1516-35982005000200007

CANO, C.C.P. et al. Produção de forragem do Capim-Tanzânia (Panicum maximum Jacq. cv. Tanzânia-1) pastejado em diferentes alturas. Revista Brasileira de Zootecnia, v.33, n.6, p.1949-1958, 2004. http://dx.doi.org/10.1590/S1516-35982004000800005

CARNEVALLI, R.A. et al. Herbage production na grazing losses in Panicum maximum cv. Mombaça pasture under four grazing managements. Tropical Grasslands, v.40, n.3, p.165-176, 2006.

http://www.tropicalgrasslands.info/index.php/tgft/pages/view/tropicalGrasslands

CUTRIM JUNIOR, J.A.A. et al. Características estruturais do dossel de capim-Tanzânia submetido a três frequências de desfolhação e dois resíduos pós-pastejo. Revista Brasileira de Zootecnia, v.40, n.3, p.489497, 2011. http://dx.doi.org/10.1590/S1516-35982011000300005

DA SILVA, S. C.; PEDREIRA, C. G. S. Princípios de ecologia aplicados ao manejo de pastagem. In: SIMPÓSIO SOBRE ECOSSISTEMA DE PASTAGENS, 3., Jaboticabal, 1997. Anais... Jaboticabal: UNESP, FCAV/FUNEP, 1997. p. 1-62.

DIFANTE, G. S. et al. Características morfogênicas e estruturais do capim-Marandu submetido a combinações de alturas e intervalos de corte. Revista Brasileira de Zootecnia, v.40, n.5, p.955-963, 2011. http://dx.doi.org/10.1590/S1516-35982011000500003

FERREIRA, D.F. Sisvar: a Guide for its Bootstrap procedures in multiple comparisons. Ciência e agrotecnologia, v. 38, n. 2, p.109-112, 2014. http://dx.doi.org/10.1590/S1413-70542014000200001

GOMIDE, C.A.M.; GOMIDE, J.A.; ALEXANDRINO, E. Características estruturais e produção de forragem em pastos de capim-Mombaça submetidos a períodos de descanso. Pesquisa Agropecuária Brasileira, v.42, n.10, 2007. http://dx.doi.org/10.1590/S0100-204X2007001000017

HUMPHREYS, L.R. Tropical pasture utilization. 1.ed. Australia: Cambridge University Press, 206p. 1991.

JANK, L.; VALLE, C.B.; RESENDE, R.M.S. Grass and forage improvement in the tropics and subtropics. In: McGILLOWAY, D.A. (Ed.) Grassland: a global resource, Wageningen: Wageningen Academic, p.69-80. 2005. 
JANUSCKIEWICZ, E.R. et al. Massa de forragem, composição morfológica e química do capim-

Tanzânia sob diferentes dias de descanso e resíduos pós-pastejo. Bioscience, v.26, n.2, p.161-172, 2010. http://www.seer.ufu.br/index.php/biosciencejournal/article/view/7046

MACEDO, C.H.O. et al. Características agronômicas, morfogênicas e estruturais do capim Panicum maximum cv. Mombaça sob desfolhação intermitente. Revista Brasileira de Saúde e Produção Animal, v.11, n.4, p.941-952, 2010. http://revistas.ufba.br/index.php/rbspa/article/viewArticle/1723

MELLO, A.C.L.; PEDREIRA, C.G.S. Respostas morfológicas do capim-Tanzânia (Panicum maximum Jacq. cv. Tanzânia-1) irrigado à intensidade de desfolha sob lotação rotacionada. Revista Brasileira de Zootecnia, v.33, n.2, p.282-289, 2004. http://dx.doi.org/10.1590/S1516-35982004000200003

MORDADO, D. et al. Porcentagem de folhas e colmos na forragem produzida pela cultura de aveia IPR 126 em função de doses de dejeto de suíno. Synergismus Scyentifica UTFPR, v.1, n.4, 2009. http://revistas.utfpr.edu.br/pb/index.php/SysScy/article/view/589

MOURA, A.M. et al. Processamento do milho para vacas leiteiras em pastejo. Arquivo Brasileiro de Medicina Veterinária e Zootecnia, v.66, n.6, p.1813-1821, 2014. http://dx.doi.org/10.1590/1678-7172

PEDREIRA, B.C.; PEDREIRA, C.G.S.; DA SILVA, S.C. Estrutura do dossel e acúmulo de forragem de Brachiaria brizantha cultivar Xaraés em resposta a estratégias de pastejo. Pesquisa Agropecuária Brasileira, v.42, n.2, p.281-287, 2007. https://seer.sct.embrapa.br/index.php/pab/article/view/7565

PEDREIRA, B.C.; PEDREIRA, C.G.S.; SILVA, S.C. Acúmulo de forragem durante a rebrotação de capim. Revista Brasileira de Zootecnia, v.38, n.4, p.618-625, 2009. http://dx.doi.org/10.1590/S1516$\underline{35982009000400005}$

PINTO, J.C.; GOMIDE, J.A.; MAESTRI, M. Produção de matéria seca e relação folha:caule de gramíneas forrageiras tropicais, cultivadas em vasos, com duas doses de nitrogênio. Revista da Sociedade Brasileira de Zootecnia, v.23, n.3, p.313-326, 1994.

http://www.revista.sbz.org.br/artigo/index.php?artigo $=454$

SANTOS, P.M. et al. Caracterização de pastagens de capins Tanzânia e Mombaça consorciados com estilosantes em ecótono de transição Cerrado: Floresta Amazônica. Revista Brasileira de Ciências Agrárias, v.6, n.1, p.163-173, 2011. http://dx.doi.org/10.5039/agraria.v6i1a817

SBRISSIA, A.F.; DA SILVA, S.C. Compensação tamanho/densidade populacional de perfilhos em pastos de capim-marandu. Revista Brasileira de Zootecnia, v.37, n.1, p.35-47, 2008.

http://dx.doi.org/10.1590/S1516-35982008000100005

SILVA, R. G. et al. Características estruturais do dossel de pastagens de capim-Tanzânia mantidas sob três períodos de descanso com ovinos. Revista Brasileira de Zootecnia, v.36, n.5, p.1255-1265, 2007. http://dx.doi.org/10.1590/S1516-35982007000600006

STABILE, S.S. et al. Características de produção e qualidade nutricional de genótipos de capim-Colonião colhidos em três estádios de maturidade. Revista Brasileira de Zootecnia, v.39, n.7, p.1418-1428, 2010. http://dx.doi.org/10.1590/S1516-35982010000700004

STOBBS, T.H. The effect of plant structure on the intake of tropical pastures. II. Differences in sward structure, nutritive value, and bite size of animals grazing Setaria anceps and Chloris gayana at various stages of growth. Australian Journal of Agriculture Research, v.24, p.821-829, 1973. http://dx.doi.org/10.1071/AR9730821

SUDENE Resolução No 115/2017. 23 de novembro de 2017. Disponível em: http://sudene.gov.br/images/arquivos/conselhodeliberativo/resolucoes/resolucao115-23112017delimitacaodosemiarido.pdf. Acesso em 27 de agosto de 2018. 